\title{
Event-related potentials and biomarkers of psychiatric diseases: the necessity to adopt and develop multi-site guidelines
}

\author{
Salvatore Campanella ${ }^{1 *}$ and Cécile Colin ${ }^{2}$ \\ ${ }^{1}$ Laboratoire de Psychologie Médicale et d'Addictologie, ULB Neuroscience Institute, CHU Brugmann-Université Libre de Bruxelles, Brussels, Belgium \\ ${ }^{2}$ Center for Research in Cognition and Neurosciences, ULB Neuroscience Institute and Laboratoire de Neurophysiologie Sensorielle et Cognitive, CHU \\ Brugmann-Université Libre de Bruxelles, Brussels, Belgium \\ ${ }^{*}$ Correspondence: salvatore.campanella@ulb.ac.be
}

Edited by:

Christoph M. Michel, University of Geneva, Switzerland

Reviewed by:

Elyse S. Sussman, Albert Einstein College of Medicine, USA

Keywords: event-related potentials, mismatch negativity, reference electrode, biomarker, psychiatry

\section{A commentary on}

Mismatch negativity and $\mathrm{P} 3 \mathrm{a} /$ reorienting complex in subjects with schizophrenia or at-risk mental state

by Higuchi, Y., Seo, T., Miyanishi, T., Kawasaki, Y., Suzuki, M., and Sumiyoshi, T. (2014). Front. Behav. Neurosci. 8:172. doi: 10.3389/fnbeh.2014.00172

Higuchi et al. (2014) published a paper comparing healthy controls, schizophrenic patients and subjects with at-risk mental state (ARMS) during an event-related potential (ERP) auditory oddball task. Results showed that ARMS subjects who transitioned to schizophrenia (Converters) disclosed diminished duration mismatch negativity amplitudes (dMMN) as compared with non-Converters before onset of illness. As the reduction of dMMN is a common finding when schizophrenic patients are compared with healthy controls (e.g., Umbricht and Krljes, 2005), the authors concluded that decreased $\mathrm{dMMN}$ amplitudes are a trait biomarker of psychosis, present before and after the development of the disease.

Nowadays, relapse rate for several psychiatric disorders remains tremendously high, suggesting a treatment gap in mental health care (Kohn et al., 2004). Therefore, in psychiatry, there is a recognized need for alternatives to psychotherapy and medication (Dobson et al., 2008). In this view, the identification of biomarkers is important to discover the biological underpinnings of a psychiatric syndrome and could assist in predicting the course of a mental illness in an individual and in tailoring treatment (Singh and Rose, 2009). Higuchi and colleagues' study (2014) is then of the greatest relevance, and the authors have to be commended for their work. Nevertheless, if we totally caution the use of ERPs as biomarkers of mental diseases (Campanella, 2013), we also would like to stress the urgent need to develop and promote multisite guidelines to record electrophysiological measures that may be compared and used across studies. Some guidelines concerning main ERP components obviously exist (e.g., Duncan et al., 2009, for MMN, P300 and N400). However, their use across studies is still not guaranteed, and this may lead, as in Higuchi and colleagues' study, to some misinterpretations of the data.

By employing duration changes in repetitive background stimulation while the patient was reading or watching videos, dMMN amplitude was found to be attenuated in several pathological disorders (for a review, Näätänen et al., 2012). According to the dominant view, MMN is the outcome of an automatic, attentionindependent, comparison process between a deviant stimulus and the memory trace formed by the sensory representation of the standard stimulus within short-term memory (Novak et al., 1990). A major clinical interest of the MMN therefore consists in recording this brain activity outside the focus of attention of the participant, to monitor the detection of any change in ongoing auditory stimulation, irrespective of where attention is directed (Duncan et al., 2009). This is of particular interest in patients with severe brain injuries or in persistent vegetative/minimal consciousness state (Kotchoubey et al., 2003), but it also triggers a crucial problem in "conscious" patients, which is to ensure that no active attention was directed to the task. Indeed, when participants selectively attend to deviant stimulations, a negativity of central cortical distribution (seen only during conscious stimulus attention), called N2b, superimposed the MMN (Patel and Azzam, 2005). Overall, auditory oddball tasks involved two negative overlapping sub-components evoked around 200 ms: the MMN and the N2b, elicited in passive vs. active conditions, and representing automatic vs. conscious processes, respectively (Naatanen et al., 2002). One main "technical" point allows ensuring that a passive auditory oddball task has generated a "pure" MMN, not contaminated by active (conscious) N2b attentional processes: MMN exhibits a phase reversal (i.e., positive polarity) over mastoid and other lateral posterior sites over the same latency range when a nose reference is used (e.g., Alho, 1995; Grimm et al., 2004), while N2b does not (e.g., Aulanko et al., 1993; Sussman et al., 2002).

This phase reversal, representing the only mean to disentangle MMN from N2b activities (see Figure $\mathbf{1}$ for illustration), has been largely replicated in studies from our laboratory (e.g., Colin et al., 2009) as well as from other research centers (see Näätänen et al., 2007 for a review). Unfortunately, this point is missing in 


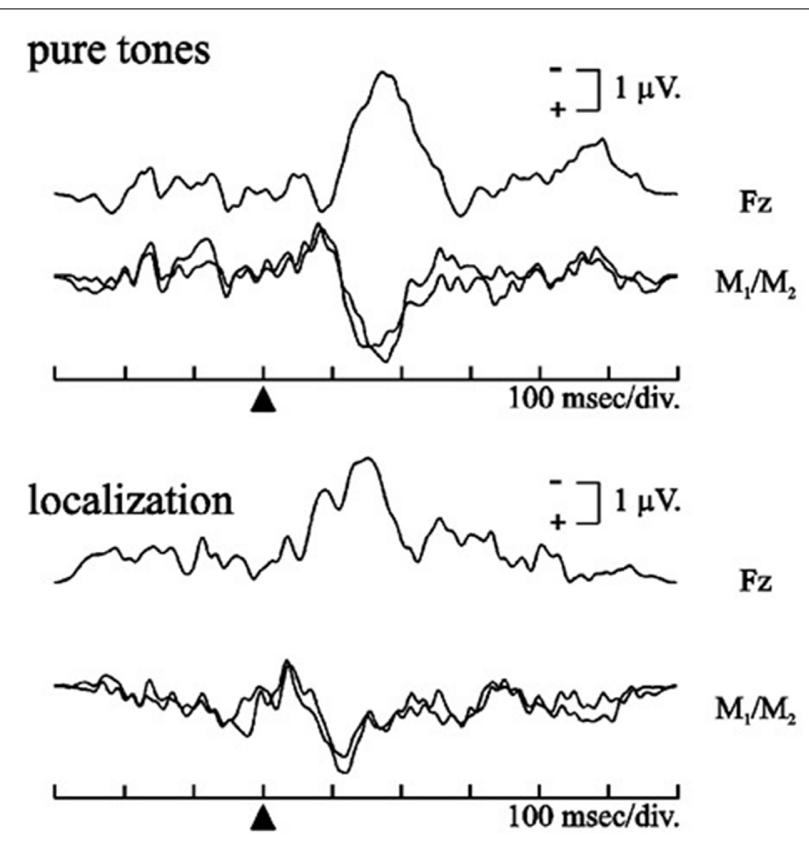

FIGURE 1 | Differential waveforms obtained in auditory oddball paradigms using a nose reference for a frequency contrast with pure tones (upper part) and for a localization contrast with syllables (lower part). The black triangle indicates sound onset. Polarity reversal between $\mathrm{Fz}$ and both mastoid (M1/M2) is clearly exhibited (adapted with permission from Colin et al., 2002).

Higuchi and collaborators' study, as electrodes were referred to the average amplitude of the ear electrodes (Higuchi et al., 2014). This clearly does not affect the conclusion that their recorded negativity allowed separating Converters from non-Converters before the onset of illness; however, it clearly question whether it is $M M N$ or $N 2 b$ amplitude reduction that should be considered as a biomarker of psychosis. As these sub-components refer to different (passive vs. active) attentional processes, this interpretation is of the greatest clinical relevance, because alterations of covert vs. overt attention processes would involve specific cognitive rehabilitative programs (Kim et al., 2009). Moreover, even if this point is minor in the paper, the authors also reported that " $\mathrm{P} 3 \mathrm{a}$ amplitudes were barely detectable" in their study (Higuchi et al., 2014). Here again the explanation could be "technical," as P3a component is usually recorded through a three-stimulus oddball task, in which "novel" events (e.g., dog barks), presented as infrequent distractors in a train of more "typical" target and standard stimuli (e.g., tones), will generate a fronto-central P3a, whereas the infrequent target stimuli will elicit a parietal P3b (see Polich, 2007 for a review). However, Higuchi et al. (2014) only used a standard/target auditory oddball task, without distractor stimuli, which is not the best suited paradigm to generate $\mathrm{P} 3 \mathrm{a}$ in passive oddball tasks (Jeon and Polich, 2001).

To conclude, we totally endorse the main objective of Higuchi and collaborators' study, which was to investigate whether a neurophysiological biomarker of psychosis onset may be found in ARMS subjects. Given their state independence, such biomarkers hold much promise in prevention research because they can be used to identify people who are at high risk of developing psychiatric disorders (Beauchaine, 2009). However, reported data also stressed that several challenges must be overcome before ERPs gain widespread use as biomarkers in psychiatry (Luck et al., 2011). Among these, the promotion of multi-site guidelines to record electrophysiological measures, notably within high-density ERP datasets (Murray et al., 2008), that may be compared and used across studies is urgent, as this could help to avoid functional misinterpretations of the data as well as to prevent from the emergence of controversial results from different laboratories.

\section{FUNDING}

The first author is funded by the Belgian Fund for Scientific Research (F.N.R.S., Belgium), but this fund did not exert any editorial direction or censorship on any part of this article.

\section{REFERENCES}

Alho, K. (1995). Cerebral generators of mismacth negativity (MMN) and its magnetic counterpart (MMNm) elicited by sound changes. Ear Hear. 16, 38-51.

Aulanko, R., Hari, R., Lounasmaa, O. V., Näätänen, R., and Sams, M. (1993). Phonetic invariance in the human auditory cortex. Neuroreport 4, 1356-1358.

Beauchaine, T. P. (2009). The role of biomarkers and endophenotypes in prevention and treatment of psychopathological disorders. Biomark. Med. 3, 1-3. doi: 10.2217/17520363.3.1.1

Campanella, S. (2013). Why it is time to develop the use of cognitive event-related potentials in the treatment of psychiatric diseases. Neuropsychiatr. Dis. Treat. 9, 1835-1845. doi: 10.2147/NDT.S53687

Colin, C., Hoonhorst, I., Markessis, E., Radeau, M., de Tourtchaninoff, M., Foucher, A., et al. (2009). Mismatch negativity (MMN) evoked by sound duration contrasts: an unexpected major effect of deviance direction on amplitudes. Clin. Neurophysiol. 120, 51-59. doi: 10.1016/j.clinph.2008.10.002

Colin, C., Radeau, M., Soquet, A., Colin, F., and Deltenre, P. (2002). Mismatch negativity evoked by the McGurk-MacDonald effect: evidence for a phonological representation within auditory sensory short term memory. Clin. Neurophysiol. 113, 495-506. doi: 10.1016/S1388-2457(02)00024-X

Dobson, K. S., Hollon, S. D., Dimidjian, S., Schmaling, K. B., Kohlenberg, R. J., Gallop, R., et al. (2008). Randomized trial of behavioral activation, cognitive therapy, and antidepressant medication in the prevention of relapse and recurrence in major depression. J. Consult. Clin. Psychol. 76, 468-477. doi: 10.1037/0022-006X.76.3.468

Duncan, C. C., Barry, R. J., Connolly, J. F., Fischer, C., Michie, P. T., Näätänen, R., et al. (2009). Event-related potentials in clinical research: guidelines for eliciting, recording, and quantifying mismatch negativity, P300, and N400. Clin. Neurophysiol. 120, 1883-1908. doi: 10.1016/j.clinph.2009.07.045

Grimm, S., Widmann, A., and Schröger, E. (2004). Differential processing of duration changes within short and long sounds in humans. Neurosci. Lett. 356, 83-86. doi: 10.1016/j.neulet.2003. 11.035

Higuchi, Y., Seo, T., Miyanishi, T., Kawasaki, Y., Suzuki, M., and Sumiyoshi, T. (2014). Mismatch negativity and $\mathrm{P} 3 \mathrm{a} /$ reorienting complex in subjects with schizophrenia or at-risk mental state. Front. Behav. Neurosci. 8:172. doi: 10.3389/fnbeh.2014.00172

Jeon, Y. W., and Polich, J. (2001). P3a from a passive visual stimulus task. Clin. Neurophysiol. 112, 2202-2208. doi: 10.1016/S1388-2457(01) 00663-0

Kim, Y. H., Yoo, W. K., Ko, M. H., Park, C. H., Kim, S. T., and Na, D. L. (2009). Plasticity of the 
attentional network after brain injury and cognitive rehabilitation. Neurorehabil. Neural Repair. 23, 468-477. doi: 10.1177/1545968308328728

Kohn, R., Saxena, S., Levav, I., and Saracero, B. (2004). The treatment gap in mental health. Bull. World Health Organ. 82, 858-866. doi: 10.1590/S004296862004001100011

Kotchoubey, B., Lang, S., Herb, E., Maurer, P., Schmalohr, D., Bostanov, V., et al. (2003). Stimulus complexity enhances auditory discrimination in patients with extremely severe brain injuries. Neurosci. Lett. 352, 129-132. doi: 10.1016/j.neulet.2003.08.045

Luck, S. J., Mathalon, D. H., O’Donnell, B. F., Hämäläinen, M. S., Spencer, K. M., Javitt, D. C., et al. (2011). A roadmap for the development and validation of event-related potential biomarkers in schizophrenia research. Biol. Psychiatry 70, 28-34. doi: 10.1016/j.biopsych.2010.09.021

Murray, M. M., Brunet, D., and Michel, C. (2008). Topographic ERP analyses: a step-by-step tutorial review. Brain Topogr. 20, 249-264. doi: 10.1007/s10548-008-0054-5

Näätänen, R., Kujala, T., Escera, C., Baldeweg, T., Kreegipuu, K., Carlson, S., et al. (2012). The mismatch negativity (MMN) - A unique window to disturbed central auditory processing in ageing and different clinical conditions. Clin. Neurophysiol. 123, 424-458. doi: 10.1016/j.clinph.2011.09.020
Näätänen, R., Paavilainen, P., Rinne, T., and Alho, K. (2007). The mismatch negativity (MMN) in basic research of central auditory processing: a review. Clin. Neurophysiol. 118, 2544-2590. doi: 10.1016/j.clinph.2007.04.026

Naatanen, R., Schroger, E., and Alho, K. (2002). "Electrophysiology of Attention," in Stevens Handbook of Experimental Psychology, 3rd Edn., ed J. Wixted (New york, NY: John Wiley \& Sons, Inc.), 601-653.

Novak, G. P., Ritter, W., Vaughan, H. G. Jr., and Wiznitzer, M. L. (1990). Differentiation of negative event-related potentials in an auditory discrimination task. Electroencephalogr. Clin. Neurophysiol. 75, 255-275.

Patel, S. H., and Azzam, P. N. (2005). Characterization of N200 and P300: selected studies of the eventrelated potential. Int. J. Med. Sci. 2, 147-154. doi: 10.7150/ijms.2.147

Polich, J. (2007). Updating P300: an integrative theory of $\mathrm{P} 3 \mathrm{a}$ and P3b. Clin. Neurophysiol. 118, 2128-2148. doi: 10.1016/j.clinph.2007. 04.019

Singh, I., and Rose, N. (2009). Biomarkers in psychiatry. Nature 460, 202-207. doi: 10.1038/ 460202a

Sussman, E., Winkler, I., Huotilainen, M., Ritter, W., and Näätänen, R. (2002). Top-down effects can modify the initially stimulus-driven auditory organization. Brain Res. Cogn. Brain Res.
13, 393-405. doi: 10.1016/S0926-6410(01) 00131-8

Umbricht, D., and Krljes, S. (2005). Mismatch negativity in schizophrenia: a meta-analysis. Schizophr. Res. 76, 1-23. doi: 10.1016/j.schres.2004 12.002

Conflict of Interest Statement: The authors declare that the research was conducted in the absence of any commercial or financial relationships that could be construed as a potential conflict of interest.

Received: 21 October 2014; accepted: 20 November 2014; published online: 10 December 2014.

Citation: Campanella $S$ and Colin C (2014) Eventrelated potentials and biomarkers of psychiatric diseases: the necessity to adopt and develop multi-site guidelines. Front. Behav. Neurosci. 8:428. doi: 10.3389/fnbeh. 2014.00428

This article was submitted to the journal Frontiers in Behavioral Neuroscience.

Copyright (c) 2014 Campanella and Colin. This is an open-access article distributed under the terms of the Creative Commons Attribution License (CC BY). The use, distribution or reproduction in other forums is permitted, provided the original author(s) or licensor are credited and that the original publication in this journal is cited, in accordance with accepted academic practice. No use, distribution or reproduction is permitted which does not comply with these terms. 